\title{
RHEUMATIC HEART DISEASE IN IDENTICAL TWINS
}

\author{
BY \\ C. BRUCE PERRY, M.D., F.R.C.P.
}

(From the Department of Medicine, University of Bristol)

It has long been recognized that acute rheumatism and rheumatic heart disease occur more frequently in some families than in others. It is, however, far from clear whether this increased incidence is due to genetic factors or to exposure to the same environment.

Paul (1931) found that the spread of the disease through families suggested that the disease was due to an infection, in which the possible rôles of environment and of an inherited disposition were undetermined. Roberts and Thomson (1934) considered that the most reasonable explanation of the family incidence of the disease was that it is due to genetically determined differences in susceptibility, but that environmental factors are necessary for the disease to become manifest in susceptible individuals. Wilson and Schweitzer (1937) from a study of the familial incidence of the disease concluded that the factor of susceptibility to rheumatic fever might be inherited as a single autosomal recessive gene. Read, Ciocco and Taussig (1938) confirmed the high frequency with which rheumatic heart disease is found in parents and siblings of rheumatic children. They considered that although their study reveals a strong familial tendency to the disease, the findings were not sufficiently definite to determine the relative importance of heredity and environment. In view of this doubt the study of rheumatic heart disease in identical twins may be of value. Morgan and Webster (1938) have already reported mitral stenosis developing after rheumatic fever in identical twins, one of whom died at the age of twenty-three from the disease. Kaufmann and Scheerer (1938) amongst the records of 8500 twins found seventy-two sets in which acute rheumatism was recorded. Twenty-seven of these were uni-ovular, and both twins were recorded as having rheumatism in only five cases; of the forty-five binovular twins concordance was observed only once.

A pair of twins both of whom apparently developed rheumatic heart disease at the same time has recently been observed.

\section{Case reports}

Pamela and Patricia B. were born in December 1932. They weighed the same at birth and their mother states that she tells them apart by their voices. They have lived together all their lives and had measles and whooping-cough together and also occasional colds and sore throats. In May 1939 Pamela had a sore throat, developed a scarlatiniform eruption and was sent to a fever 
hospital with scarlet fever. Following the scarlet fever she had no joint pains, but developed carditis and was in hospital for nine weeks. When first seen, fifteen weeks after the onset of the scarlet fever, her apex beat was diffuse and forcible in the fifth space in and beyond the mid-clavicular line. There was a loud systolic murmur at the apex. Patricia, who was examined at the same time, gave a history of tonsillitis when her sister had scarlet fever, but she developed no rash and was kept at home. She had no joint pains, but on examination her apex beat was diffuse and forcible in the fifth space in the mid-clavicular line and there was a loud apical systolic murmur. X-rays show that Pamela's heart had a more convex left border and was slightly larger than Patricia's.

Electrocardiograms are closely alike.

The evidence on which this pair is considered monozygotic is as follows:

Facial appearance similar-mother finds difficulty in distinguishing them. Hair and eye colour identical.

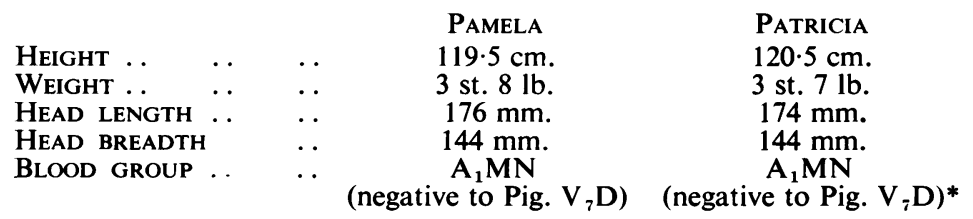

FINGER-PRINTS. Right hand: first, second and third fingers similar according to Stocks' method. Left hand: first and third fingers similar. There is, in addition, a crossed similarity between Patricia's right little finger and Pamela's left. The number of resemblances between the right and left hands of the two children is four. Dr. Percy Stocks, to whom the finger-prints and other data were submitted, writes: 'I agree with your results for this pair, and from the finger-prints alone I should expect them to be dizygotic. The photographs and measurements seem to point to the other conclusion. I should feel doubtful about classing this pair as monozygotic.' In an attempt to settle this doubt $\mathrm{X}$-rays of the twins' wrists, elbows, ankles and knees were made to see if there were any difference in the ossification of the epiphyses. All were identical with the exception that the pisiform bone was ossified in Pamela's left wrist but in neither of Patricia's, and that all Pamela's bones show a marked 'white line' near the end of the diaphysis, presumably the result of the scarlet fever.

Actually the number of resemblances in the finger-prints by no means rules out a diagnosis of monozygocity, as is clear from Dr. Stocks' papers (1930, 1933). In addition to the identical facial appearance the children also display remarkable resemblances in movements and mannerisms. In view of this, the measurements and the fact that the mother herself sometimes finds it easy to mistake them, it seems highly probable that the pair is in fact monozygotic.

This pair presents the picture of rheumatic carditis developing with no recognized arthritis in both children following what was almost certainly a throat infection with the same haemolytic streptococcus. One developed a rash and was subsequently treated differently from the other, yet both developed the same type of rheumatic attack and are left with a similar cardiac lesion. In this pair it would appear that given the necessary infection the development of acute rheumatism, and further the form which the attack took, was largely determined by genetic factors. At the same time, the response to the erythrogenic toxin produced by the infecting organism was clearly different in the two

* Pig. $\mathrm{V}_{7} \mathrm{D}$ is a new blood group antibody being investigated by the Galton Laboratory. 
patients, since one developed a well-marked rash and in the other any rash which occurred was so slight that it escaped notice.

The second pair of twins to be considered are Harry and Fred H., who were born in October 1929. Fred had chicken-pox as a baby, but Harry escaped although they slept together throughout the illness. They had measles in early childhood. At the age of five years and three months Harry had acute appendicitis and an 'enlarged inflamed appendix with a faecolith in the distal third' was removed. Fred had his appendix removed when he was six years and two months old; it was described as 'long and kinked' and contained a faecolith. The boys had been together all their lives except for these two illnesses. In August 1938 Harry was admitted to the Children's Hospital under the care of Dr. N. L. Price, to whom I am indebted for the following particulars. He was taken ill on August 3 with pain and swelling in the knees, later the ankles, elbows and wrists were affected. When admitted on August 17 there was only slight cardiac enlargement with an apical systolic murmur. Later a diastolic murmur developed. He was in hospital until November 7.

When first seen, in December 1938, there was a nodule on the right elbow. The apex beat was in the fourth intercostal space in the mid-clavicular line and there was a loud apical systolic murmur with a diastolic murmur at the aortic area and down the left sternal border. He was given a further period of rest and six weeks later the nodule had disappeared. The signs in the heart were unchanged except that the apical systolic murmur was softer. Since then he has remained well and there has been no change in the cardiac signs.

Fred was first examined in July 1939. He had no illness at the time his brother had acute rheumatism. On examination his heart was normal. Radiology shows that both have a similarly shaped heart, but that Harry's left ventricle is slightly larger. Their electrocardiograms are closely alike.

The evidence on which a diagnosis of monozygotic twins is based is as follows:

Facial appearance alike. Hair and eye colour identical. Both have a congenital sinus on the pinna of the right ear (a familial feature).

\begin{tabular}{|c|c|c|c|}
\hline & & Fred & HARRY \\
\hline HEIGHT & . & $125.5 \mathrm{~cm}$. & $124.5 \mathrm{~cm}$. \\
\hline WEIGHT .. & .. & 4 st. & 4 st. \\
\hline HEAD LENGTH .. & . & $170 \mathrm{~mm}$. & $175 \mathrm{~mm}$. \\
\hline HEAD BREADTH.. & .. & $152 \mathrm{~mm}$ & $149 \mathrm{~mm}$. \\
\hline BLOOD GROUP ... & .. & $\begin{array}{c}\mathrm{A}_{2} \mathrm{MN} \\
\text { (negative to Pig. } \mathrm{V}_{7} \mathrm{D} \text { ) }\end{array}$ & $\begin{array}{c}\mathrm{A}_{2} \mathrm{MN} \\
\left.\text { (negative to Pig. } \mathrm{V}_{i} \mathrm{D}\right)\end{array}$ \\
\hline
\end{tabular}

FINGER-PRINTS. Right hand: first, fourth and fifth fingers similar. Left hand: first, second, third and fifth fingers similar. Dr. Stocks stated that some of the finger-prints were not clear enough to be sure of, but that the number of resemblances was six or seven. He had no doubt that the pair is monozygotic.

This pair shows the development of acute rheumatism and carditis with permanent damage to the aortic valve in only one of the twins. Thus, despite the same genetic constitution and the fact that the twins had been brought up and had lived nearly all their lives together, some undetermined factor caused an attack of rheumatism in one while the other escaped. Since diet, clothing, and housing were, as far as can be determined, identical in the two boys, chance exposure to infection appears to be the most probable way in which this could occur. 


\section{Summary and conclusions}

Two pairs of apparently identical twins are described. In the first both children suffered a similar rheumatic attack following a sore throat, which in one only produced scarlet fever. In the second, one child only developed acute rheumatism and carditis although they had been brought up together. It is concluded that while heredity is of considerable importance in the causation of acute rheumatism, another factor, probably infection, plays an equally if not more important rôle.

Thanks are due to Mr. F. W. Willway and Mr. A. A. Dowling, the Surgical Registrars of the Bristol Royal Infirmary and Bristol Children's Hospital, for the information as to the appendicectomies in the second pair. I am also greatly indebted to Dr. G. L. Taylor of the Galton Laboratory, who kindly grouped the bloods, to Dr. Percy Stocks for advice on the finger-prints, and to Dr. Fraser Roberts, without whose help and advice the investigation of the twins would have been far less complete.

\section{REFERENCES}

Kaufmann, O., and Scheerer, E. (1938). Z. menschl. Vererb.-u.-Konst. Lehre, $21,687$. Morgan, J. E., and Webster, S. J. (1938). J. Amer. med. Ass., 110, 1744.

Paul, J. R. (1931). J. clin. Invest., 10, 53.

Read, F. E. M., Ciocco, A., and Taussig, H. B. (1938). Amer. J. Hyg., 27, 719.

Roberts, J. A. F., and Thomson, W. A. R. (1934). Ann. Eugen., Camb., 6, 3.

Stocks, P. (1930). Ibid., 4, 49.

and Kara, M. (1933). Ibid., 5, 1.

Wilson, M. G., and Schweitzer, M. D. (1937). J. clin. Invest., 16, 555. 